九州大学学術情報リポジトリ

Kyushu University Institutional Repository

\title{
Variations of Acidity in the Peel of Acid Citrus. I. Acid Contents in the Flavedo and Albedo of Acid Citrus
}

Widodo, Soesi ladi E.

Fruit Science Laboratory, Faculty of Agriculture, Kyushu University

Shiraishi, Mikio

Fruit Science Laboratory, Faculty of Agriculture, Kyushu University

Shiraishi, Shinichi

Fruit Science Laboratory, Faculty of Agriculture, Kyushu University

https://doi.org/10.5109/24111

出版情報 : 九州大学大学院農学研究院紀要. 40 (3/4)，pp. 257-262, 1996-03. Kyushu University バージョン：

権利関係 : 


\title{
Variations of Acidity in the Peel of Acid Citrus. I. Acid Contents in the Flavedo and Albedo of Acid Citrus
}

\author{
Soesiladi E. Widodo, Mikio Shiraishi and Shinichi Shiraishi \\ Fruit Science Laboratory, Faculty of Agriculture \\ Kyushu University, Fukuoka 811-23, Japan \\ (Received October 2, 1995)
}

\begin{abstract}
Seasonal changes in free acid (FA) and combined acid (CA) contents in the flavedo and albedo of Kabosu (C. sphaerocarpa Hort. ex Tanaka), Yuzu (Citrus junos Sieb. ex Tanaka), Hanayu (C. hanayu Hort. ex Shirai), 'Lisbon' lemon (C. limon Burm. f. Lisbon) and Sudachi (C. sudachi Hort. ex Shirai) were investigated to elucidate differences in the patterns of acid accumulation. Based on the accumulation of FA and CA contents, and $\mathrm{pH}$ changes in the flavedo and albedo, the pattern of acid accumulation in the flavedo of Kabosu and Yuzu was different than that in the flavedo of Hanayu, 'Lisbon' lemon and Sudachi. The FA contents in the flavedo of Kabosu and Yuzu increased and the CA contents decreased, resulting in high FA contents in later sampling dates. The CA contents in the flavedo of Hanayu, 'Lisbon' lemon and Sudachi was kept higher than the FA contents. No pattern differences were found in the albedo of acid citrus investigated.
\end{abstract}

\section{INTRODUCTION}

Among many acid citrus grown in Japan, Yuzu (Citrus junos), Kabosu (C. sphaerocarpa), and Sudachi (C. sudachi) dominate both in planted area and production (Kitagawa, 1994). Lemon (C. limon Burm.) is cultivated in Japan, but it is mostly imported, ranked second after orange of imported citrus fruits (Kitagawa, 1994). No data on planted area and production of Hanayu (C. hanayu) has been reported, eventhough it is cultivated and also highly appreciated due to its excellent fragrance. Reports on their juice qualities are accumulated, but very limited reports on the chemical characteristics other than essential oils of their peel are on record.

Unlike citrus juice, organic acids in citrus peel saps are present in the salt form and not in the free state, resulting in a low free acid content and a high combined acid content detected in citrus peel extracts by most workers. Our gas chromatographical determinations on several Japanese acid citrus (Widodo et al., 1995) showed a high portion of citric acid in the flavedo of Kabosu and Yuzu. Reports on volatile components of citrus peel are numerous due to the fact that peel is the main source of essential oils contributing to fragrance. However, reports on acidity of the peel of acid citrus other than that of acid lemon are limited. Even if it is available, no discrimination between flavedo and albedo is reported (Yamaki, 1989). It is known that there is a synergistic effect between a -tocopherol and ascorbic acid or citric acid as antioxidants (Sinclair, 1984). Therefore, a different pattern of acid accumulation found in the flavedo of Kabosu and Yuzu (Widodo et al., 1995) is of interest. to be further elucidated. A such report is hardly found.

Seasonal changes in acidity of acid lemon and several Japanese acid citrus were 
investigated and presented in the present paper to elucidate differences in the patterns of acid accumulation.

\section{MATERIALS AND METHODS}

Acid citrus investigated were Hanayu (Citrus hanayu), Kabosu (C. sphaerocarpa), Sudachi ( C. sudachi), 'Lisbon' lemon (C. limon), and Yuzu (C. junos). The fruits were tagged when they were about $1 \mathrm{~cm}$ in diameter. Ten fruits were monthly sampled beginning from September 16, 1994 to December 16, 1994 from trees grown in the Fruit Trees Experiment Station (FTES) of Kyushu University at Sasaguri, Fukuoka, Japan. The fruits of Sudachi were monthly sampled from the Fukuoka Agricultural Research Center (FARC) at Chikushino, Fukuoka, Japan. Cultural practices and climatic conditions may affect fruit characteristics. To see if the pattern of acidity in the peel of Kabosu and Yuzu is different in both locations, the fruits of Kabosu and Yuzu were sampled in both locations at the same sampling dates. The fruits were quicky brought to our laboratory and were once kept refrigerated. Extractions of flavedo and albedo were accomplished in 1-3 days after sampling dates.

Flavedo and albedo of the fruits were separately peeled and chopped. As many as 50 $\mathrm{g}$ of each fractions was added with about $150 \mathrm{ml}$ water and then homogenized. The slurry homogenate was centrifuged at 2,500 rpm for 20 minutes. The supernatant was decanted into a $200 \mathrm{ml}$ flask and mixed up with water; the water used was destilled-deionized one. About $100 \mathrm{ml}$ of the supernatant was quickly freezed for further analyses.

Ten $\mathrm{ml}$ of each flavedo and albedo extracts were directly titrated with $0.1 \mathrm{~N} \mathrm{NaOH}$ and phenolphthalein as indicator and their free acid contents (titratable acidity) were determined. The titrated solutions were passed through a column $(1.6 \mathrm{~cm} \mathrm{I}$. D. $\times 4 \mathrm{~cm})$ of cation-exchange resin Amberlite IR-120, washed with water until about $40 \mathrm{ml}$ solutions were obtained. The total acid contents were determined as in the free acid determination. Combined acid content was a difference between total and free acid contents. Measurements were run in triplicate. The acid contents were calculated as $\mathrm{mg}$ citrate/g fresh weight. Following the determinations of acid contents, $\mathrm{pHs}$ of flavedo and albedo extracts were measured.

\section{RESULTS AND DISCUSSION}

Unlike citrus juice in which organic acids are mostly present in the free state, citrus peel is usually characterized by having a high content of organic acids in the salt form, not in the free state, resulting in a low free acidity when it is titrated with a strong base (Sinclair and Eny, 1947). The data of Yamaki (1989) of 88 different citrus species and cultivars, 87 citrus investigated showed a low percentage of free acidity in the peel, strongly supported the usual phenomena of acidity in citrus peel. One citrus he investigated, Yuzu, showed 58.3\% free acidity. Such an unusual percentage, unfortunately, was not given attention.

Our data graphed in Fig. 1 reconfirmed our preliminary gas chromatographical data of 

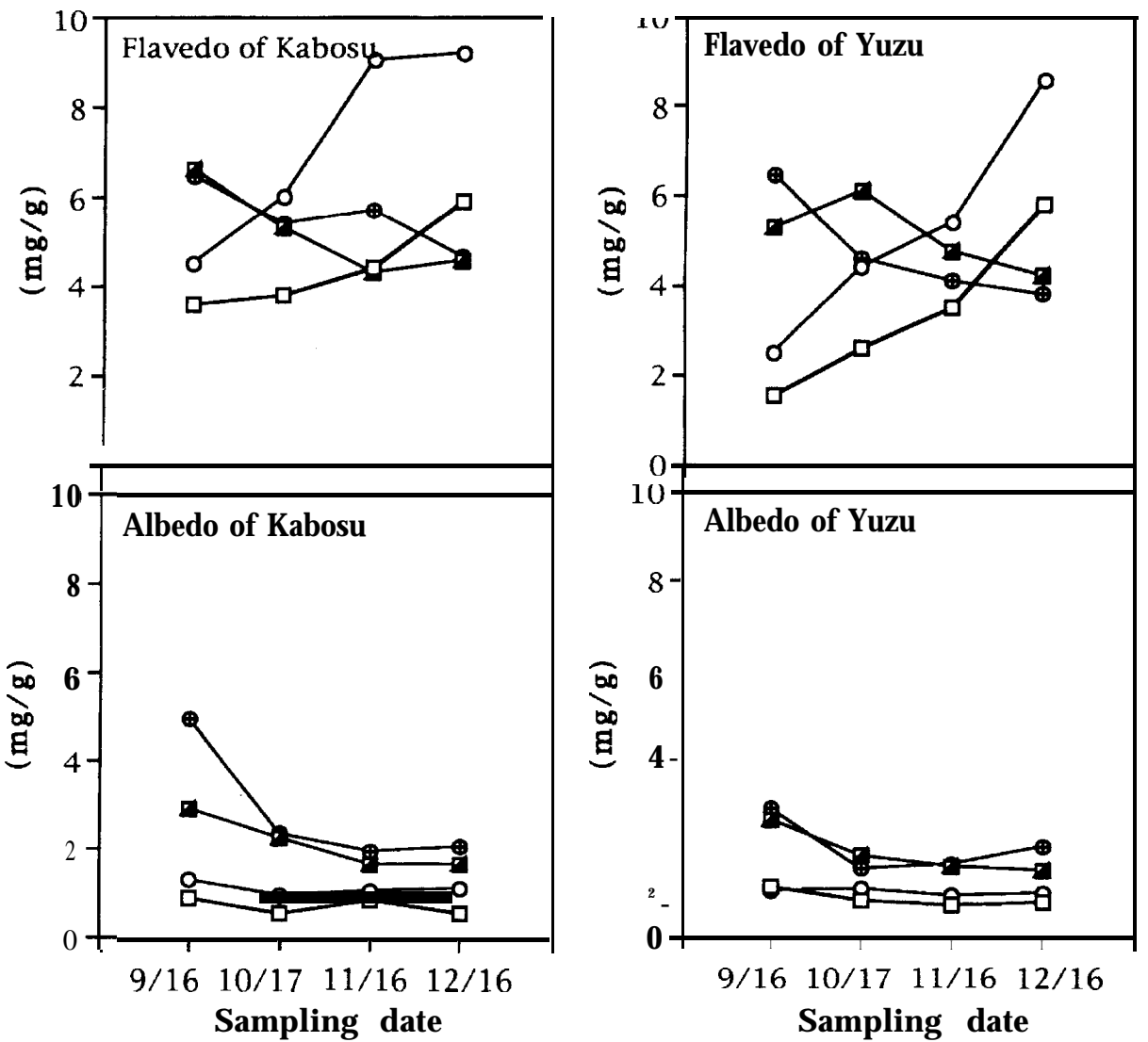

$\longrightarrow$ - FA (FTES) -.…… CA (FTES)

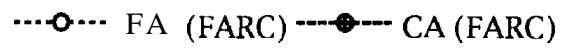

Fig. 1. Seasonal changes in free acid (FA) and combined acid (CA) contents in the flavedo and albedo of Kabosu and Yuzu. FTES = Fruit Trees Experiment Station of Kyusyu University, FARC $=$ Fukuoka Agricultural Research Center.

a high free acid content in the flavedo of Kabosu and Yuzu (Widodo et al., 1995), and clearly showed that the pattern of acid accumulation in the flavedo of both Kabosu and Yuzu (Fig. 1) is different than that in the flavedo of Hanayu, 'Lisbon' lemon and Sudachi (Fig. 2). The free acid contents in the flavedo of Kabosu and Yuzu were continually increasing while the combined acid contents were decreasing from September 16 to December 16, resulting in high free acid contents in the later sampling dates. The pattern of acid accumulation in the flavedo of Hanayu, 'Lisbon' lemon and Sudachi followed the usual pattern that is the combined acid content was kept higher than the free acid content (Fig. 2).

Figure 1 shows also that the free acid content in the flavedo of Kabosu from FARC began to surpass the combined acid content in October 17, about 1 month ealier than in the flavedo of Kabosu from FETS. The same pattern was also observed in the flavedo of Yuzu. The results show clearly that eventhough the acid concentrations were different in 


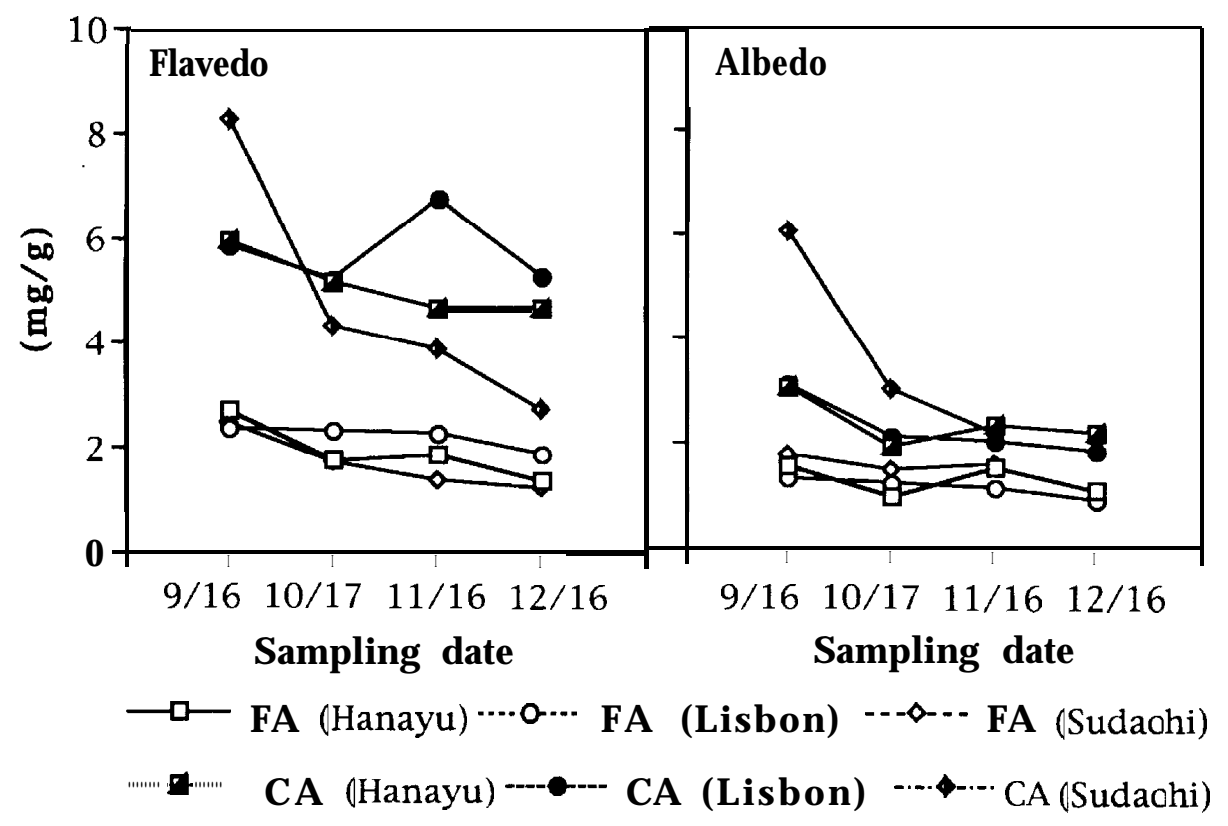

Fig. 2. Seasonal changes in free acid (FA) and combined acid (CA) contents in the flavedo and albedo of Hanayu, 'Lisbon' lemon, and Sudachi.

both locations, Kabosu and Yuzu showed an increasing free acid content and a decreasing combined acid content in both locations. It indicates that differences in cultural practices and climatic conditions did not affect, their pattern of acid accumulation.

The differences in acid accumulation found in the flavedo of the acid citrus investigated were not found in the albedo (Fig. 1 and 2). The albedo of all citrus investigated kept showing higher combined acid content than free acid content throughout the sampling dates. Both free and combined acid contents in the albedo were significantly lower than in the flavedo.

Figure 3 shows seasonal changes in the pHs of flavedo and albedo extracts of the acid citrus investigated. The results support the differences in the pattern of acid accumulation in the flavedo shown in Fig. 1 and 2. The pHs of flavedo of Hanayu, 'Lisbon' lemon, and Sudachi increased, and those of Kabosu and Yuzu decreased up to December 16. The $\mathrm{pHs}$ of albedo fluctuated, but comparing to those of flavedo they were all relatively constant, reaching $\mathrm{pH}$ of $4.95-5.90$ in the last sampling date. The higher the $\mathrm{pH}$ of the natural extract, the less free acid it contains (Sinclair, 1984).

To the best of our knowledge, differences in acid accumulation in the flavedo of citrus fruit have not been reported. A voluminous nature of albedo might hide the differences in flavedo when acidity is measured by combining them as peel. Or the differences will not be observed when sample is taken only once so that a high percentage of free acid content in the peel of citrus fruit will be observed only by chance, and 

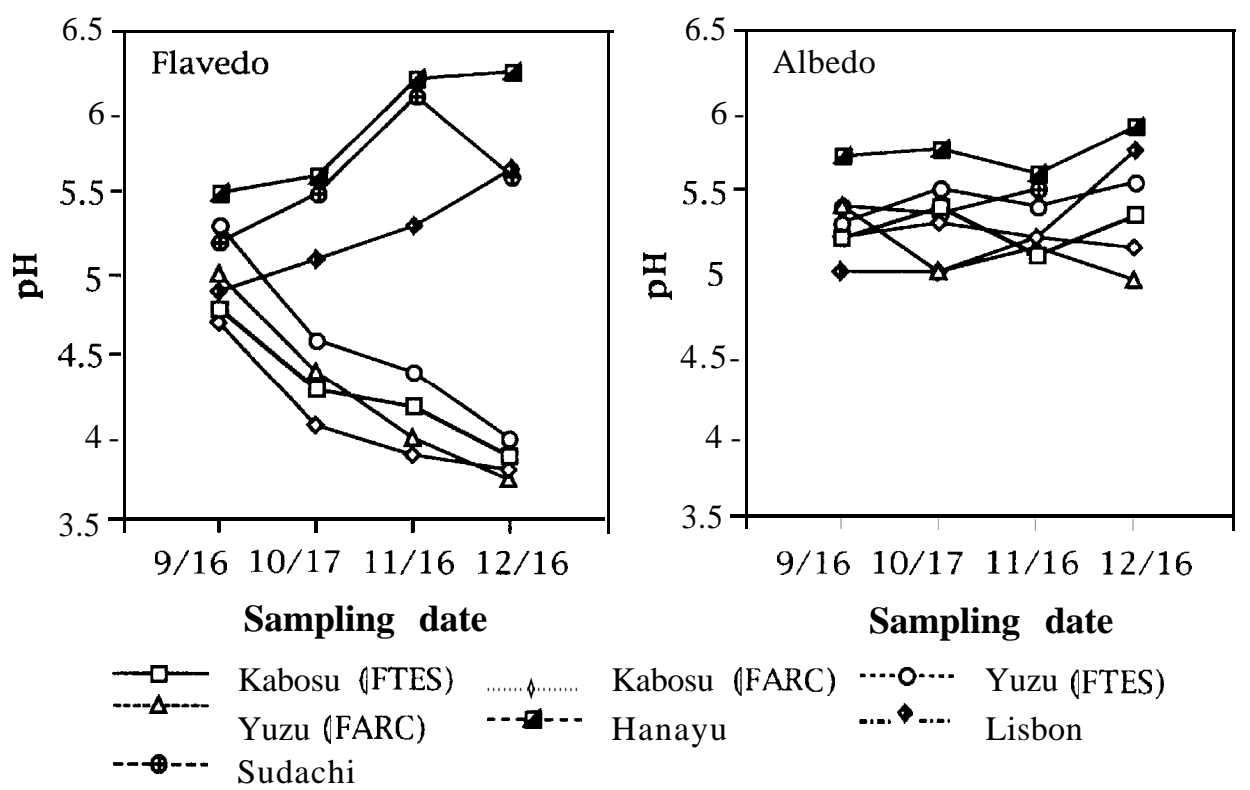

Fig. 3. Seasonal changes in the $\mathrm{pH}$ of flavedo and albedo of Kabosu, Yuzu, Hanayu, 'Lisbon' lemon, and Sudachi. See notes in Fig. 1.

consequently, attention might not be properly paid to (see Yamaki, 1989).

Significant differences in acid accumulation in the flavedo of Kabosu and Yuzu compared to the other acid citrus investigated are of interest. The immediate precursors of organic acids are, in general, other organic acids or sugars (Ulrich, 1970). A continuing increase of free acid content in the flavedo of Kabosu and Yuzu, however, might not be due to a direct consumption of sugars because no differences in sugar accumulation, whether as sugar content or composition, were found in the flavedo of acid citrus investigated (data not shown). There are still arguments whether organic acids present in the fruit are clue to translocation from the other parts or due to synthesis within the fruit itself (see Ulrich, 1970). In citrus fruits, however, evidence has accumulated which suggests that organic acids are synthesized within the fruits rather than translocated from sites of formation in the leaves (see Kefford and Chandler, 1970). Our data presented in Fig. 1 suggest that differences in acid accumulation in the flavedo of acid citrus investigated were unlikely due to differences in organic acid translocation from leaves or roots. Flavedo of citrus fruits has been shown to be independently capable of photosynthetic and dark assimilations (Bean and Todd, 1960). Differences in enzyme activities for $\mathrm{CO}$, fixation have also been reported in sweet and sour lemon preparations (Bogin and Wallace, 1966) resulting in a high accumulation of citric acid in sour lemon (Citrus limon Linn.) but low in sweet lemon (C. limettiodes). 
Japanese acid citrus such as Kabosu, Yuzu, and Sudachi are highly appreciated due to their excellent fragrance. The flavedo of citrus fruits has been reported to contain much more $\alpha$-tocopherol than albedo (Sawamura et al., 1986). It is known that there is a synergistic effect between $\alpha$-tocopherol and ascorbic acid or citric acid as antioxidants (Sinclair, 1984). In studying the effect of SO, on orange oil oxidation, Beard et al. (1972) found that the presence of citric acid reduced the rate of oxygen absorption by orange oil. Therefore, a continuing increase of acidity in the flavedo of Kabosu and Yuzu might be an advantage.

\section{ACKNOWLEDGEMENTS}

The authors wish to thank Dr. Akira Wakana of the Fruit Trees Experiment Station of Kyushu University, Sasaguri, Fukuoka and Mr. Yoshiki Oba of the Fukuoka Agricultural Research Center, Chikushino, Fukuoka, Japan for the fruits used in this study.

\section{REFERENCES}

Bean, R. C. and G. W. Todd 1960 Photosynthesis and respiration in developing fruits. I. $\mathrm{C}^{14} \mathrm{O}$ uptake by young oranges in light and in dark. Plant Physiol, 35: 425-429

Beard, J. H., B. C. Fletcher and E.C. H. van Beresteyn 1972 The enhancement of orange oil oxidation by sulphur dioxide. J.Sci. Food Agric., 23: 207-213

Bogin, E. and A. Wallace 1966 Organic acid synthesis and accumulation in sweet and sour lemon fruits. Proc Amer. Soc. Hort Sci, 89: 182-194

Kefford, J. F. and B. V. Chandler 1970 The Chemical Constituents of Citrus Fruits. Academic Press, New York.

Kitagawa, H. 1994 Horticultural Statistics of Japan. In "Horticulture in Japan" ed. by Organizing Committee XXIVth International Horticultural Congress Publication Committee. Asakura Publ. Co.. Ltd., Tokyo, pp. 9-13

Sawamura, M., A. Bandoh, N. Ohta, and H. Kusunose 1986 Seasonal changes of isoprenoid related substances in citrus peels. Nippon Shokuhin Kogyo Gakkaishi., 33: 566-571

Sinclair, W. B. 1984 The Biochemistry and Physiology of the Lemon and Other Citrus Fruits. Univ. of California, Division of Agriculture and Natural Resources, California, USA.

Sinclair, W. B. and D. M. Eny 1947 Ether-soluble organic acids and buffer properties of citrus peels. Bot. $\mathrm{Gaz}$, , 108: 398-407

Llrich, R. 1970 Organic Acid. In "The Biochemistry of Fruit and Their Product" ed. by A. C. Hulme. Academic Press, London, pp. 89-118

Widodo, S. E., M. Shiraishi and S. Shiraishi 1995 Organic acids in the flavedo and albedo of acid lemon and Japanese acid citrus by gas chromatography. J.Fac. Agr., Kyushu Univ, 40: 29-37

Yamaki, Y. T. 1989 Variation in acidity and acid content in rind among citrus fruits, and their relationship to fruit juice acidity. J. Japan. Soc. Hort. Sri., 57: 568-577. 